accident, and who was admitted 30 minutes after the accident. Four months after the operation active contraction appeared in the flexor muscles of the forearm, and thereafter strength increased progressively. At 11 months 2-point discrimination, temperature, and light-touch sensations were present in all the fingers, while at 20 months the strength in the biceps, pronator teres, and opponens pollicis was about $30 \%$ to $40 \%$ of normal and in the flexors of the fingers and wrist about $80 \%$ of normal. Abduction of the shoulder was possible to $75^{\circ}$, and normal flexion of the elbow was possible, though it lacked $10^{\circ}$ full extension. The boy could lift $10 \mathrm{lb}$. $(4.5 \mathrm{~kg}$.) weights and write his name. Malt and McKhann performed another successful replacement of an arm in September, 1963, but chronologically the honour of the second case must go to C. W. Ch'en and his colleagues in Shanghai. ${ }^{7}$ Their patient, a 27-year-old man, was able to write and to play ping-pong after 7 months. Since then Ch'en and his colleagues have carried out two further successful replacements. ${ }^{8}$

The decision to carry out replacement must be assessed anew in every case. The value of the part to be replaced depends on position-thus in general the arm is progressively more valuable from shoulder to hand, but the reverse is true for the leg. A prosthesis may offer the prospects of rapid rehabilitation and a useful artificial limb. The patient must be active, with a healthy attitude towards his injury, and should not have extensive injuries elsewhere. The prognosis is better with a cleanly severed limb than with one that has been avulsed, since avulsion may stretch nerves or injure nerve roots. Without refrigeration a limb can probably survive for 4 to 6 hours, but Malt and McKhann recommend that the limb should be wrapped in aluminium foil or plastic sheeting and immersed in a mixture of ice and saline: this procedure, they believe, may increase the viability up to 18 hours. Before operation thrombus must be removed from major arteries and veins of the limb by removing obvious clots with instruments and by "milking" the limb with pressure. Perfusion of the main artery with heparinized Ringer's solution or with low-molecular-weight dextran will also help to clear the vessels of sludged and altered blood. It is essential from the first to achieve bony fixation, usually by excision of small pieces of bone and by intramedullary nailing of the main fragments. It may be necessary to shorten the bone to allow approximation of nerves and blood vessels without tension. The veins are then anastomosed, followed by the arteries ; any dead or devitalized parts of the walls of the vessels should be removed, and a graft (for example, of a saphenous vein) may be necessary to bridge the defects. Most workers in this field consider that primary suture of nerves should be undertaken. Attention should then be paid to the soft tissues, with the removal of dead tissue; skin grafting may be undertaken immediately or within a few days, the type of graft depending on the extent of the skin loss. The patient should be given tetanus prophylaxis and antibiotics. Post-operatively the limb should be splinted and elevated, and passive movement of joints should start early.

Replacement operations make considerable demands on all concerned, including the patient, who may be turned by a prolonged stay in hospital into a psychological cripple. The

1 Frost, H. M., Clin. Orthop., 1963, 29, 29.

2 Brit. med. F., 19к0, 2, 1001 .

- Ibid., 1964, 1, 514 .

- Mehl, R. L., Panl, H. A., and Beattie, E. J., jun., Lancet, 1964, $2,1419$.

S Snyder, C. C., and Knowles, R. P., Clin. Orthop., 1963, 29, 113.

- Malt, R. A., and McKhann, C. F., 尹. Amer. med." Ass., 1964, 189, 716.

' Ch'en, C. W., Ch'ien, Y. C., and Pao, Y. S., Chin. med. Ұ., 1963, 82, 632.

- Horn, J. S., Lancet, 1964, 1, 1152

- Shaw, R. S., Clin. Orthop., 1963, 29, 56. aim must be to ensure a better result by repair than would be produced by amputation and an artificial limb. Thus, even with increased knowledge and experience on the part of surgeons, the operation seems unlikely to become commonplace. As R. S. Shaw ${ }^{9}$ points out, the fascination of the possibility of accomplishing a surgical stunt must not obscure the surgeon's view of accomplishing his primary object-the maximum degree of rehabilitation for his patient.

\section{The Olympic Games}

What are the limits of human performance? Athletes at the Olympic Games soon to begin at Tokyo will probably extend some of them. But are we near the end of recordbreaking runs and jumps ? ${ }^{1}$

This seems to be a common view. In $1926 \mathrm{~A}$. V. Hill published his famous book Muscular Activity, ${ }^{2}$ incorporating the studies conducted on athletes at Princeton. A graph shows average speed in the then world records plotted against distance. It seemed unlikely then, so smooth is the resultant curve, that any substantial alteration would occur. But in fact there has been a considerable increase in speed in every event, and the improvement continues. So we must resist the temptation to say we have arrived, or nearly arrived, at the ultimate goal unless we have good scientific reasons based on the structure of the body, speed of muscle action, and other factors. At present it appears to be too difficult to make the calculations with sufficient accuracy. Nevertheless, examining the rate of change in performance provides some guide to the future, and proportional as well as absolute change appears to be greater in the long-distance and endurance events. We seem to be nearer the limit in the 100 yards than in the mile; improved performance is even greater in the long-distance events-20,000 to 30,000 metres.

Why performance continues to improve is uncertain. A number of factors probably play a part, but there is no certainty about the degree to which they contribute. Perhaps the most obvious is that the population from which athletes are drawn has greatly increased since the modern Games were first held in 1896. The number of countries taking part has increased steadily, the population of the countries has increased, and within each country there has probably been an increase in the number taking part in athletics.

Average height and weight have been increasing in those countries where measurements have been made, and the implication is that athletes in general are stronger to-day than 50. years ago. The anthropometry of the Olympic athlete was studied in detail by J. M. Tanner at the 1960 Olympic Games. ${ }^{3}$ If comparable work had been done in 1910 it would have been possible to determine whether there had been significant changes in the body size and conformation of the athlete. As a record alone, therefore, Tanner's investigation is of value. It will be possible in the future to make such comparisons. A limited study of athletes was

2 See Brit. med. 9., 1960, 2, 721.

2 Hill, A. V., Muscular Activity. Baltimore. 1926.

Tanner, J.M., The Physique of the Olympic Athlete. London. 1964.

- Kohlrausch, W., 1929, Arbeirsphysiol., 2, 187.

Krogh, A., The Axatomy and Physiology of the Capillaries. Yale University Press. 1922 .

- Hensel, H., and Hildebrandt, G., in Handbook of Physiology, Section 4: Adaptation to the Emvironment, p. 73. Washington, D.C., American
Physiological Society. 1964. 
carried out by W. Kohlrausch ${ }^{4}$ in 1928 , and his results and Tanner's agree in general, but the 1928 athletes were considerably smaller. It is not surprising that Tanner finds considerable differences between athletes, but it is remarkable how similar are the athletes in any one event. Photographs in his book show a Japanese and an Australian who were distinguished in the triple jump; they are almost identical. It would be difficult for anyone looking through the illustrations in Tanner's book to pick out the athletic type, for there are so many types.

The final reason for the continual improvement in performance is the one that most coaches would support-namely, better and more efficient training methods. This is the hardest to investigate retrospectively and there is little objective evidence available. It is certainly true that top athletes to-day spend more time training and practising than was customary even 25 years ago. And training now continues for most, if not all, of the year. This illustrates one of the problems concerning amateur status. Anyone wanting to become an Olympic athlete will have great difficulty in training for it and at the same time earning a living in an occupation other than athletics. Tanner's conclusion is that, "Performances have improved not only because of better training and better competition, but because we have better systems for finding the most suitable men to become athletes."

Not many world records are established at the Olympic Games, and there are a number of possible reasons, including the psychological strain, the unfamiliar setting, and the physical environment. Yet though the last Games were held in Rome in hot and humid weather Olympic records were set up in the majority of events and there were several world records.

In Tokyo the climate may be rather similar to Rome, but the Olympics in 1968 will be held in Mexico at an altitude of about $7,500 \mathrm{ft}$. $(2,300 \mathrm{~m}$. $)$. It seems highly probable that performance in track events, particularly long-distance events, will be adversely affected. Sprinters may be all right because the 100 -metres race is run mainly on anaerobic metabolism. Jumpers and throwers may even benefit, since the reduction in the partial pressure of oxygen should not have much effect on the explosive muscular effort, and the reduced density of the air should slightly improve performance. No doubt there will be requests for advice from coaches and athletes which will not be too easy to meet. What training regimen or procedure can be suggested for those who live at sea-level ? Here is an unusual problem for research, since at present the physiologist finds it difficult to discover any unequivocal effects of altitudes as low as 7,500 ft. However, the performance of football teams from England in Mexico City has in general been poor enough to suggest that there is some physiological deterioration.

But this is far from being the only research problem of the athlete. In many countries to-day research institutes have been established primarily to study athletes. Yet surprisingly little is done in Britain, especially in view of the outstanding contributions made in the past by A. V. Hill, J. Barcroft, and others, as well as our history of athletic achievement. Many questions, physiological and clinical, deserve attention. It is obviously important to know the characteristics of the man who is supreme in a particular event ; then we can learn what the human body can do. What is the largest cardiac output, the highest oxygen consumption, the greatest muscle power of which man is capable ? And the changes that take place in training are of greater interest. It is surprising that we still do not properly understand how training improves performance. We are uncertain even of the changes occurring in muscle itself. A. Krogh ${ }^{5}$ in his classic work showed that the capillaries increased in number in a muscle when it was trained, and similar findings have been reported from studies on various animals. Such changes have not yet been found in man, and the mechanism responsible is obscure, though lack of oxygen has been suggested as the cause of them. When a muscle increases in strength as a result of training, do the fibres increase in size or in number? The evidence suggests the former but is not conclusive. And the possible modifications in the nervous control of muscular contraction are only. now suspected. ${ }^{6}$

Much of this and other information is needed for the rational treatment of muscle injuries, muscle atrophy, and damage to motor nerves. The list of problems could be expanded to fill several pages, but only two more will be given. What is meant by physical fitness and how can it be measured ? Is muscular exercise necessary for health; if so, how much and why ? Many may feel the first part of the last question is unnecessary and is already clearly established, but it is not easy to find adequate evidence. There is a good case for believing that muscular work over a considerable period of life lowers the likelihood of coronaryartery disease, but it is not proved. It is no longer believed that athletes commonly suffer from "strained" hearts, and there is the negative information that athletes live as long as non-athletes.

Despite widespread interest in this subject British athletes, seeing what is done for their colleagues abroad, wonder why they are relatively neglected here. The Central Council of Physical Recreation, the British Association of Sport and Medicine, the Fitness and Training Section of the Ergonomics Research Society are all, in their several ways, doing their utmost to encourage research. But athletic performance is a difficult and time-consuming subject to investigate, and at present there are not enough research workers willing to turn their hand to it.

\section{Safer Cars}

Of the many factors that contribute to cause read accidents one of the most easily remediable is bad design of motor vehicles. Human failure of some sort is doubtless of prime importance in most accidents. And after long neglect the adaptation of an antiquated road system to modern needs is being undertaken. But to design vehicles which are both acceptable to customers and less likely to cause serious injuries in a collision would seem to be a contribution worth making. Consequently it was thought timely to hold a conference earlier this year on "Safety in Motoring," with special reference to design of vehicles in relation to injury. The British Medical Association, the Royal College of Surgeons, and the Society of Motor Manufacturers and Traders sponsored it. Medical men and motor engineers took part ; the Minister of Transport wished it well in an opening address; and its report is published this week. ${ }^{1}$

Among the distinguished medical men who spoke, Professor W. Gissane and Dr. John Bull, of the Birmingham Accident Hospital, emphasized the exceptionally high fatality rate of

\footnotetext{
1 Safety in Motoring. British Medical Association. 1964. 5s. net.

2 Gissane, W., and Bull, J., Brit. med. F., 1964, 1, 75.

s Ibid., 1964, 1, 69.
} 